\title{
Investigation of the constancy of the MWCNTs on the fibres surface for manufactured self-sensing composites
}

\author{
Mohammed Al-Bahrani ${ }^{1,2}$, Zoltan J Gombos ${ }^{3}$, Alistair Cree ${ }^{1}$ \\ ${ }^{1}$ Mechanical Engineering, School of Engineering, University of Plymouth, Plymouth, PL4 8AA, UK \\ ${ }^{2}$ Iraqi ministry of oil, Baghdad, Iraq \\ ${ }^{3}$ Exeter Advanced Technologies, University of Exeter, Exeter, EX4 4QF, UK \\ Email: mohammed.naeem@plymouth.ac.uk
}

\begin{abstract}
Different methods have been used to deposit the Multi-walled carbon nanotubes (MWCNTs) onto the fibre surface to fabricate self-sensing composites. However, the constancy of the MWCNTs onto the fibre surfaces during infusion processing still unclear. In this study, we have deposited MWCNTs onto the glass fibre surface by two methods to investigate the state of MWCNTs during and after epoxy infusion processing. In the first method, the glass fibres were directly coated with the MWCNTs and in the second method, an adhesive was used to coat the glass fibre surface before depositing the MWCNTs over it. Rectangular specimens for both types of self-sensing composites were cut from different zones and then tested. The results showed that the self-sensing composites with adhesively bonded MWCNTs exhibited more consistent in their properties than the composites where no adhesive was used. In addition, the electrical resistance of both types of self-sensing composites was monitored during the epoxy infusion process. The results showed that the electrical resistance was no obvious affected for composite with non-adhesive bonded MWCNTs and was high for the specimens where the MWCNTs were not adhesively bonded. Moreover, the numerical study was also conducted and the results indicated that the relationship between the volume fraction of the MWCNTs and their tunnelling distance was an inverse. A recent study has proven that the properties of the self-sensing composites are strongly dependent on the method that used to deposit the MWCNTs on the surface of glass fibres layers.
\end{abstract}

Keywords; Smart composites; MWCNTs; Mechanical and Electrical properties; Self-sensing composites, Resistance monitoring. 


\section{Introduction}

Glass fibre reinforced polymer composites are used in a variety of industries such as the military, aerospace and energy sectors $[1,2]$. This is primarily due to their many attractive properties such as having good specific stiffness, good specific strength and their good anticorrosion response in most normal operating environments [3]. Recently, many attempts have been made to fabricate a smart composite for structure health monitoring applications which can sense any internal changes when it exposed to external loads. For example, crack initiation and propagation [4], gas leakage detection in energy applications [5], and possible pressure and strain variations [69]. Uniform filler dispersion in a self-sensing composite is very important to get a homogenous in mechanical properties along the composite structure as well as to get reliable electrical resistance values if the structure is being exposed to external loads [10]. Therefore, such improved mechanical and electrical properties are essential to keep the smart composite functioning even after being subjected to changes in operating conditions where high static and cyclic loading and temperature variations may be encountered.

To overcome these potential problems, it may be necessary to improve the strength and toughness of the composite by incorporating additional strengthening materials, but without affecting the weight of the composite. Carbon nanotubes (CNTs), discovered by Ijima in 1991 [11], have been widely used in this role as a nanoscale filler to reinforce a number of different composites in order to create a self-sensing, and strong, composite. Such a response can be achieved since CNTs possess excellent mechanical, electrical, optical and thermal properties [1217]. This unique combination of electrical and mechanical properties, in addition to their morphological features (high aspect ratio and nanoscale), have made them an excellent candidate material for this purpose. To use CNTs in this way, they must somehow be incorporated into the fibre composite. This can be achieved in two ways;

(i) By adding the CNTs directly into the resin matrix material and

(ii) By impregnating the surface of fibre with the CNTs in order to improve the mechanical properties in that region as well as to make it electrically conductive.

With regards to the matrix modification technique, Chang [18] studied the mechanical properties of GFRP/epoxy composite laminates with embedded multi-walled carbon nanotubes (MWCNTs) and compared the results obtained with the unmodified composite. His results showed that a significant improvement of the mechanical properties of the composite was 
achieved, especially with regards to the flexural and impact strengths, which increased by 22.1 $\%$ and $44.3 \%$ respectively, when compared to the unmodified GFRP laminate condition. Wei et al [19] added CNTs to epoxy resin in order to develop a smart nanocomposite material. The results they obtained showed a good improvement in the Young's moduli (E) which increased by $62.6 \%$ (from $2.5 \mathrm{GPa}$ to $6.69 \mathrm{GPa}$ ). The material also displayed a good response to strain, generating a gauge factor of about 2.68. However, significant agglomeration issues were observed, caused by adding a high concentration CNTs, so increasing the viscosity of the matrix resin and this issue is also observed by other study as well [20].

This processing problem remains the major challenge yet to be fully addressed. In addition, using a large quantity of CNTs during the fabrication of a large component or structure will markedly increase the manufacturing cost. Coating the fibre surface with CNTs, as suggested here, could significantly reduce this cost penalty. Several approaches have been employed to directly coat the composite fibre surfaces instead of adding them to the resin matrix. These methods include direct growth [21], electrophoretic deposition (EPD) [22], dip coating [23] and gun spray lay-up [24]. All such methods have successfully deposited the CNTs onto the fibre surface and have improved composite properties. For example, Niels et al [21] deposited the CNTs directly on the fabric surface using a chemical vapour deposition (CVD) technique in order to strengthen the weak interface region between the fibre and matrix. The obtained results showed improvement of the composite properties. Deng et al [22], used electrophoretic deposition (EPD) to embed the CNTs on the fibre surface. Their study, using scanning electron microscopy (SEM), showed surface roughening of the reinforcing fibres so leading to a change in the fibres natural surface morphology. This method enhanced the interlaminar shear strength (ILSS) of the resulting composite by $60.2 \%$, when compared to normal processing. In general, the main purpose of these fibre surface treatments is to eliminate the outer surface layer of the fibre, which is often seen as a weak region, so increasing the reactivity of the reactive groups at the interfacial surface region $[25,26]$.

However, the mechanical stability of MWCNTs on the surface of fibre has yet to be fully understood. Most researchers have concentrated only on the nature of the deposition of MWCNTs onto the fibre surface without fully exploring the changes to both the mechanical and electrical sensing properties of the resulting glass fibre/MWCNT/epoxy composite. Therefore, the main aims of this study are firstly; to investigate the use of a fixing adhesive on the glass fibre surface which holds the MWCNTs in their desired location during the resin infusion 
process. Secondly; to investigate any variations in the mechanical, electrical and strain sensitivity properties (viz. any property gradient) along the composite panel length in addition to performing a numerical study to investigate the changes in the tunnelling distance between MWCNTs in relation to their volume fraction along the composite panel length.

\section{Experimental Procedures and Materials}

The multi-wall carbon nanotubes (MWCNTs) used in this study were a CVD synthesized variety obtained directly from the manufacturer (US-Research Company, USA). These are shown in Figure 1. These CNTs had a mean diameter of approximately $50 \mathrm{~nm}$ and an average length of 20 $\mu \mathrm{m}$. Their purity was $>95 \%$ with a density of $\approx 2.1 \mathrm{~g} \cdot \mathrm{cm}^{-3}$. The reinforcing glass fibres used in the test panels were of a commercial plain-woven E-type glass, of the density of $2.54 \mathrm{~g} . \mathrm{cm}^{-3}$. The epoxy matrix resin was slow curing EL2 laminate (bisphenol-A) type with a density of 1.15 g.cm ${ }^{3}$. In addition, a low viscosity resin and curing hardener (type AT30) were chosen which are widely used in many industrial applications. The adhesive used to fix the MWCNTs to the fibre surface was a simple adhesive spray (Fusion Fix GP Spray Adhesive). The E-glass fibres, the epoxy resin and the adhesive were all supplied by the same company (Easy Composite Co, Ltd, $\mathrm{UK})$.

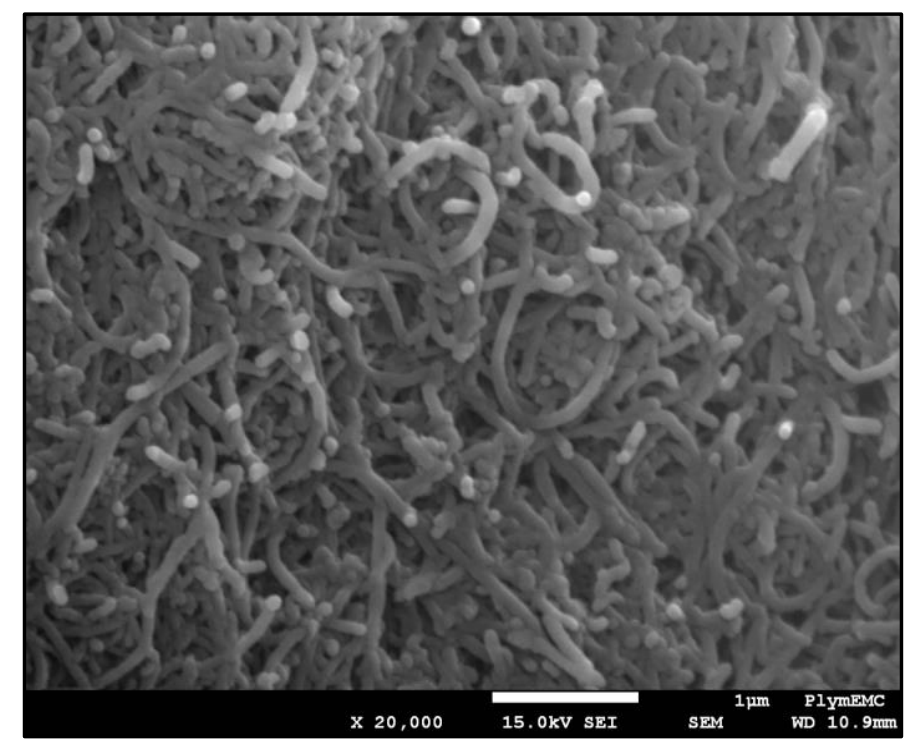

Figure 1. SEM morphology of as-received MWCNTs. 


\subsection{Specimen Manufacture}

To prepare the MWCNTs/glass/epoxy composite (i.e. MWCNTs - GE), the composite laminate layers panels were prepared individually using vacuum assisted resin infusion. Figure 2 below shows the preparation steps used during the procedure.

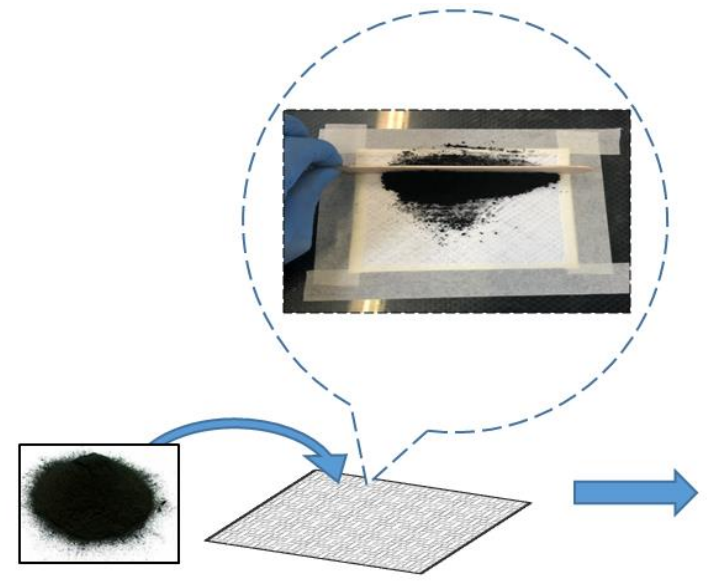

MWCNTs (0.1g)
MWCNTs Copperfoil

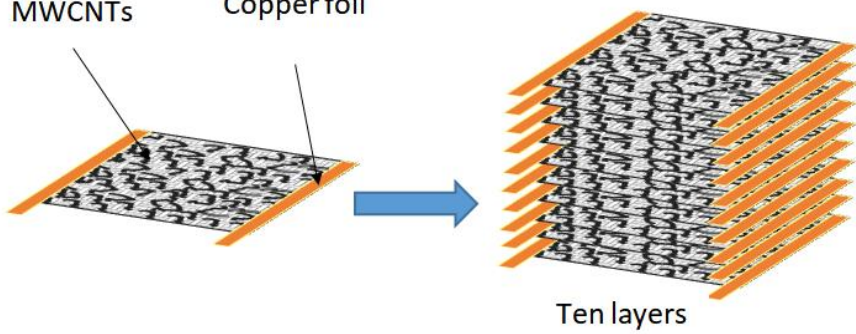

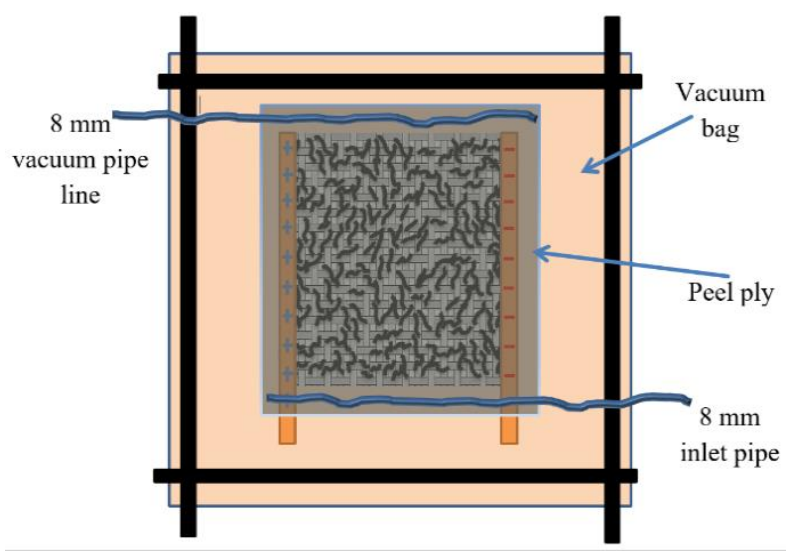

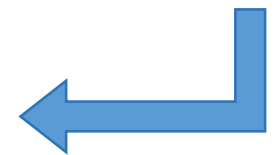

Figure 2. Schematic illustration of MWCNTs depositing on the top surface of composite layers (for both groups with and without adhesive) and then stacked together for vacuum assisted resin infusion.

Firstly, a pre-measured mass of MWCNTs (starting from $0.1 \mathrm{~g}$ ) was spread manually on the surface of glass fibres, using a wooden spatula, to make them electrically conductive. This process was continued until the MWCNTs covered all of the surface area of the composite layer. In this way, a low electrical resistance (i.e. at $0.4 \mathrm{~g}$ of MWCNTs $\approx 613 \Omega$ ) was produced. 
Therefore, each layer consists of $0.4 \mathrm{~g}$ MWCNT, resulted in $4 \mathrm{~g}$ in case of the applied 10 layers, which equal to $10 \mathrm{wt}$. \% of the total fabric weight. During this procedure, care was taken to ensure that no clumping of the MWCNTs occurred on the surface. The dimensions of each coated square specimen area were $32 \mathrm{~cm} \times 24 \mathrm{~cm}$. For the targeting tests panels, $20 \mathrm{such}$ layers were prepared. From these, two test panels, comprising 10 layers each, were then manufactured. This ensured that each test panel had a nominal thickness of $\approx 2 \mathrm{~mm}$, as required by the flexural tests which were conducted according to standard BS EN ISO 14125:2011E [54].

These panels were then divided into two groups; one group was coated only with MWCNTs, the second group had the MWCNTs fixed into place using the adhesive. For the second group, the adhesive was applied to the fibre surface before the resin infusion took place. To ensure that a uniform distribution of the MWCNTs was obtained, the MWCNTs were sprinkled very carefully manually onto the adhesive layer. These techniques are shown in Figure 2. For electrical resistance monitoring, copper conductive tape was attached to the edge of each layer for both groups (with and without adhesive applied). This step carried out in order to facilitate the monitoring of the electrical resistance changes which was taken place during the processing. Control samples were also fabricated from 10 layers of glass fibre and epoxy resin by infusion resin processing. The virgin glass fibre/epoxy (GE) composites had $\approx 50-50 \%$ volume fraction of epoxy resin and glass fabric.

\subsection{Mechanical and Electrical Characterisation}

\subsubsection{Mechanical Tests}

Flexural tests were carried out on the prepared specimens in accordance with BS EN ISO 14125:2011E [54] using a three-point bend configuration. These tests were conducted on an Instron (5582/UK195) 100 KN Universal Testing Machine operating under displacement control with a crosshead speed of $3 \mathrm{~mm} / \mathrm{min}$ along a span length of $80 \mathrm{~mm}$. The dimensions of the test specimens were $100 \times 15 \times 2 \mathrm{~mm}$ respectively. Three samples, taken from three zones shown in Figure 3, were tested to provide a more accurate average response.

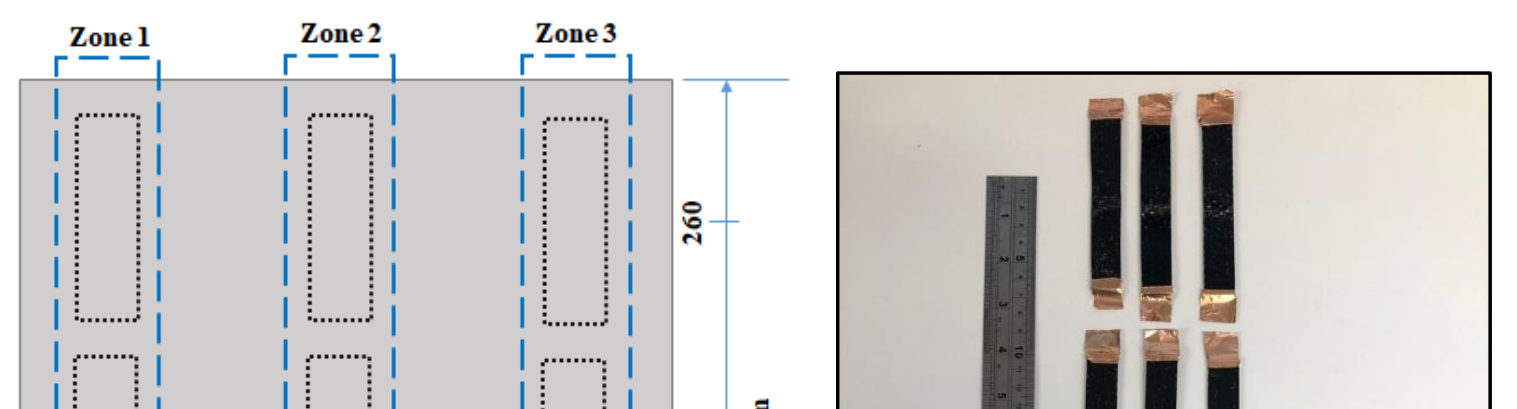




\subsubsection{Electrical Tests}

For the electrical testing of the specimens, a DC digital multi-meter (type Agilent 34401A) was used to take the measurements. The electrical conductivity $(\sigma)$ of samples was calculated using the standard equation $\sigma=L / R A$ where, $L$ is the sample length in $\mathrm{mm}$ and $R$ is the resistance in ohms $(\Omega)$ and $A$ indicates the cross-section area of the sample in $\mathrm{mm}^{2}$. A silver conducting paste was used to coat the tip of each specimen to minimize the contact resistances encountered. The three samples tested $(10 \times 10 \times 2) \mathrm{mm}$ were taken from five different zones positioned along the sample length starting from the infusion inlet to the end of the MWCNTs-GE composite panels as presented in Figure 4. To quantify the strain sensitivity (via gauge factor), the piezo resistive response of MWCNTs-GE composite was calculated for composite samples subjected to flexural loading. The electrical resistance was measured at two contact points during the test, as shown in Figure 5b. The gauge factor was calculated from the equation $G F=\left(\Delta R / R_{0}\right) \times \varepsilon^{-1}$. Where, $\Delta \mathbf{R}$ $=\left(R-R_{0}\right)$ is the changes in resistance caused by the applied load. $R_{0}$ is the initial sample resistance without applied any applied strain. $\varepsilon$ is the applied strain. 


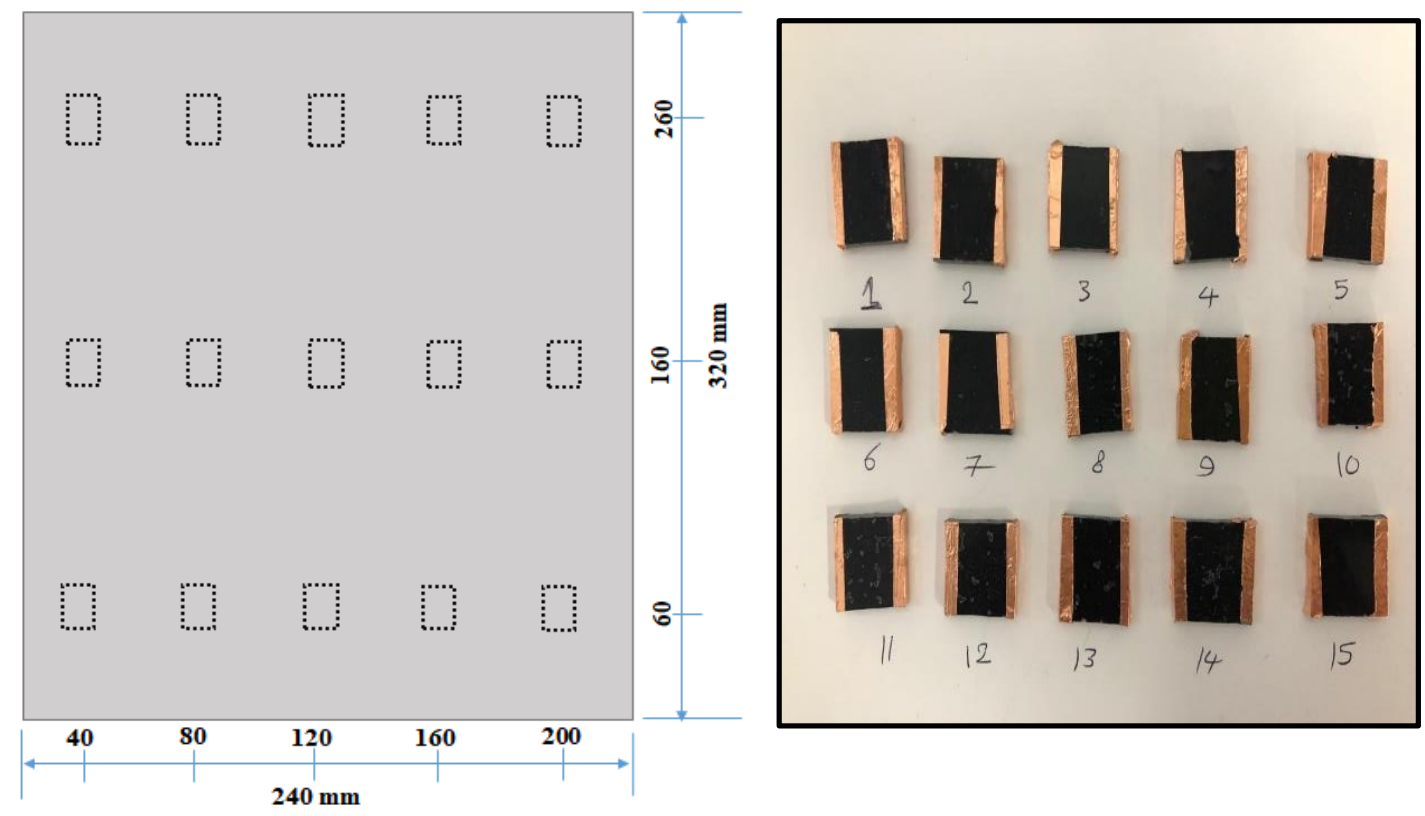

Figure 4. Schematic illustration of samples collected positions along the panel (left) and the prepared specimens for electrical conductivity test (right).

To monitor the real-time resistance changes taking place during infusion, both types of prepared composite test panels (as explained above) were used. To record the changes in electrical resistance, multi-meter probes were connected to the test panels using copper tape on the sides of the MWCNTs treated zone. During the infusion process, the flow rate of the epoxy resin was maintained at a constant $1 \mathrm{~cm} \cdot \mathrm{min}^{-1}$ in order to allow enough time to collect the necessary multimeter readings as shown in Figure 5. Scanning electron microscopy (SEM JEOL JSM-7001F, Japan) was also used to investigate the degree of dispersion of the MWCNTs on the fibre surface. The SEM operated at an accelerating voltage of $15 \mathrm{kV}$, to ensure an appropriate magnification to clearly visualise the MWCNTs in situ. The samples were coated with gold to reduce sample charging. In addition, the optical microscopy was also used to capture some images in order to show the state of MWCNTs along the whole length of the samples. 


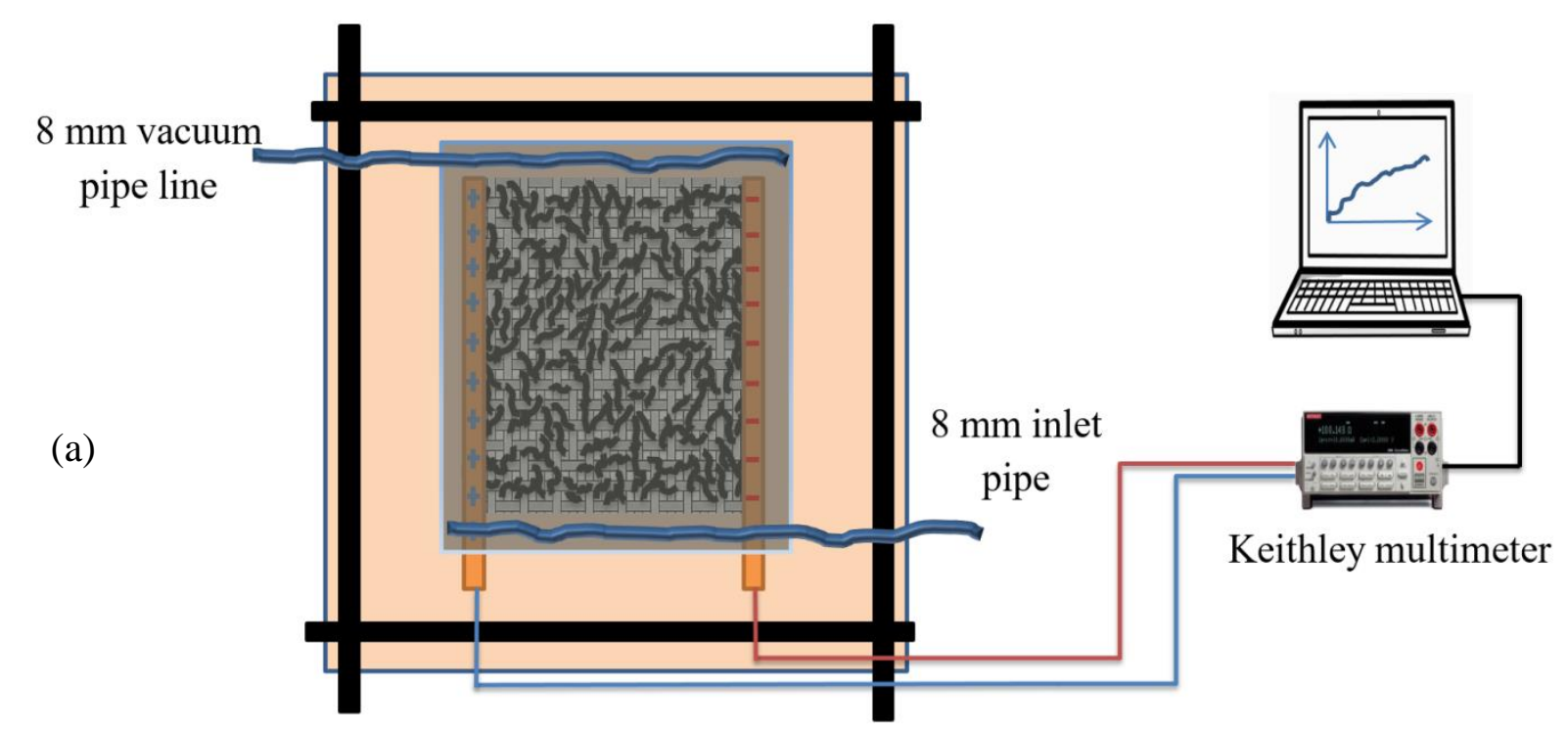

(b)

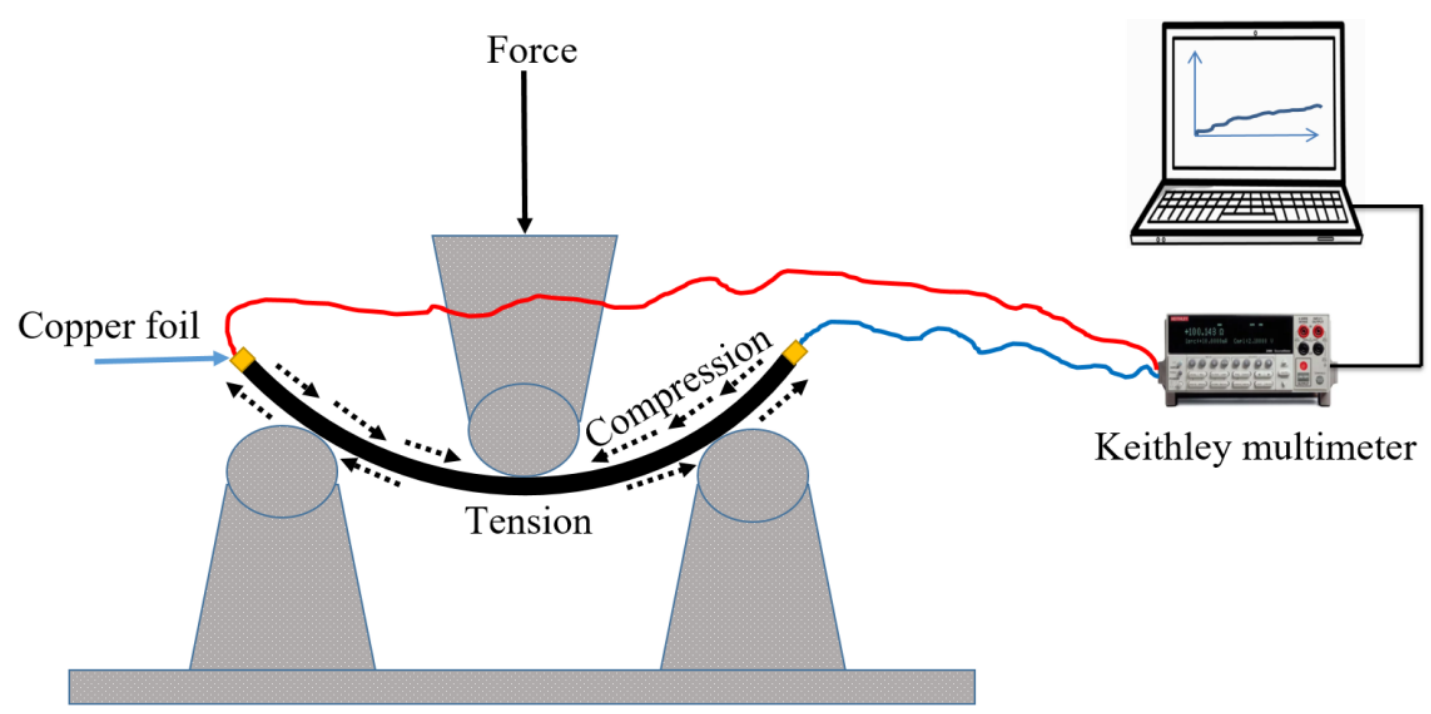

Figure 5. Illustration of the in-situ resistance monitoring of the MWCNTs deposited composite during (a) epoxy infusion and (b) flexural test.

\section{Results and Discussion}

\subsection{Mechanical Properties}

For the MWCNTs shown in Figure 6, it was speculated that they could possibly drift during the infusion process. To investigate this possibility, test specimens were taken from different 
positions along the length of a test panel and then subjected to flexural tests. The test samples were chosen from three different zones $(70 \mathrm{~mm}, 140 \mathrm{~m}$ and $210 \mathrm{~mm}$ ) along the panel length from the infusion point respectively as shown in Figure 6.

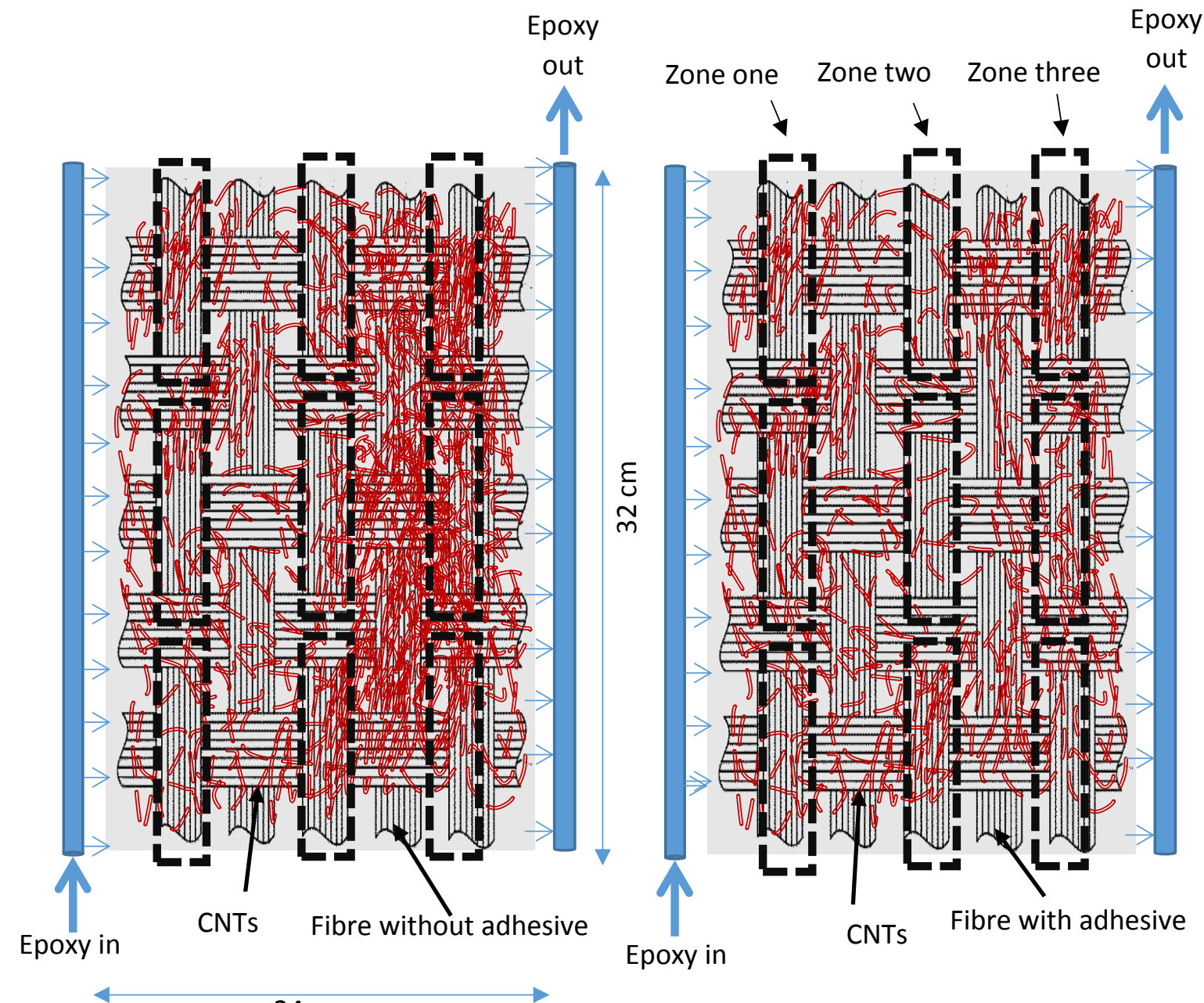

(a)

(b)

Figure 6. Schematic diagram used to explain the mobility the MWCNTs, with respect to time. (a) Without adhesive, (b) With adhesive.

Mechanical properties including flexural strength and elastic modulus were determined for both types of fabricated MWCNTs- GE composite using the standard flexural test. Figure 7a, d shows the static flexural stress-strain curves obtained for both types of composites (with and without adhesive) at the different zones along the composite panel. The changes in flexural strength, elastic modulus versus the locations of collected samples are shown in Figure $7 \mathbf{b}, \mathrm{c}$, e and $\mathrm{f}$, respectively. 
As shown in Figure 7a, d, both composites samples exhibited approximately similar stressstrain relationship for each zone tested. The flexural stress-strain curves present an almost linear response for the flexural stress up to $\approx 200-250 \mathrm{MPa}$ for MWCNTs-GE composite (without adhesive) and $\approx 350-400 \mathrm{MPa}$ for MWCNTs-GE composite (with adhesive). In Figure $7 \mathbf{b}$, e, it can be seen, regardless of whether adhesive bonding was used or not, that the deposition of the MWCNTs on the fibre surface develops a significant increase in the flexural strength of the resultant MWCNTs-GE composite when compared to the unmodified (virgin) condition. These tests indicated that for the case of MWCNTs-GE composite, where no adhesive bonding was used, a gradual, and linear, increase in the flexural strength occurred along the length of the test panel. At the start position zone one (i.e. at $70 \mathrm{~mm}$ ), the flexural strength was $373.2 \mathrm{MPa}$ and at zone three (i.e. at $210 \mathrm{~mm}$ ) the flexural strength was $429.3 \mathrm{MPa}$, so indicating a $\approx \mathbf{1 3 \%}$ and $\approx$ $26 \%$ increase for zone one, and zone three compared to control samples, respectively.

This increase is due to the drift of the MWCNTs caused by the infusion process which creates an increase in the areal density of MWCNTs along the panel length. Figure 8 shows evidence on this effect by using scanning electron microscopy (SEM) and optical microscopy, the advancing MWCNT front is clearly observed. Where the case of MWCNTs-GE composite with adhesive bonding was used to fix the MWCNTs in place, the flexural strength was higher and remained reasonably constant at $504.3 \mathrm{MPa}$, a less than $1.6 \%$ change. Clearly, the use of bonding adhesive improves the interfacial matrix/fibre properties, so keeping the MWCNTs in place. The improvement of the interfacial zone between the nanocomposite components is important to helps the load to be transferred easily through them [27, 28]. This maintains a constant areal density along the panel length. Currently, no studies in the literature have considered the influence of MWCNTs drifting, during processing, on the mechanical properties of MWCNTsGE composites. In addition, the flexural modulus of MWCNTs- GE composite also increased following the addition of the MWCNTs as shown in Figure 7c, f. The flexural elastic modulus of both MWCNTs-GE composites varied in accordance with the specimen's location zone. These changes were highest where no adhesive was used. The elastic modulus steadily increased when the location of the specimen changed from zone one to zone three. 
The significant increase in the observed mechanical properties for both MWCNTs-GE composites is due to the greatly improved interfacial bonding that exists between the reinforcement material and the surrounding matrix [29]. This improvement was greatest for (adhesive) MWCNTs-GE composite, due to the inclusion of the adhesively bonded MWCNTs in this region, which facilitates better load transfer from the matrix to the fibre reinforcement. The observed variation in the mechanical properties along the panel length can be attributed to the drift of MWCNTs from zone one to zone three, caused by the epoxy infusion flow pressure as shown in Figure 8. In this study, the boundary between the two phases is called drift line and highlighted with a white line. 

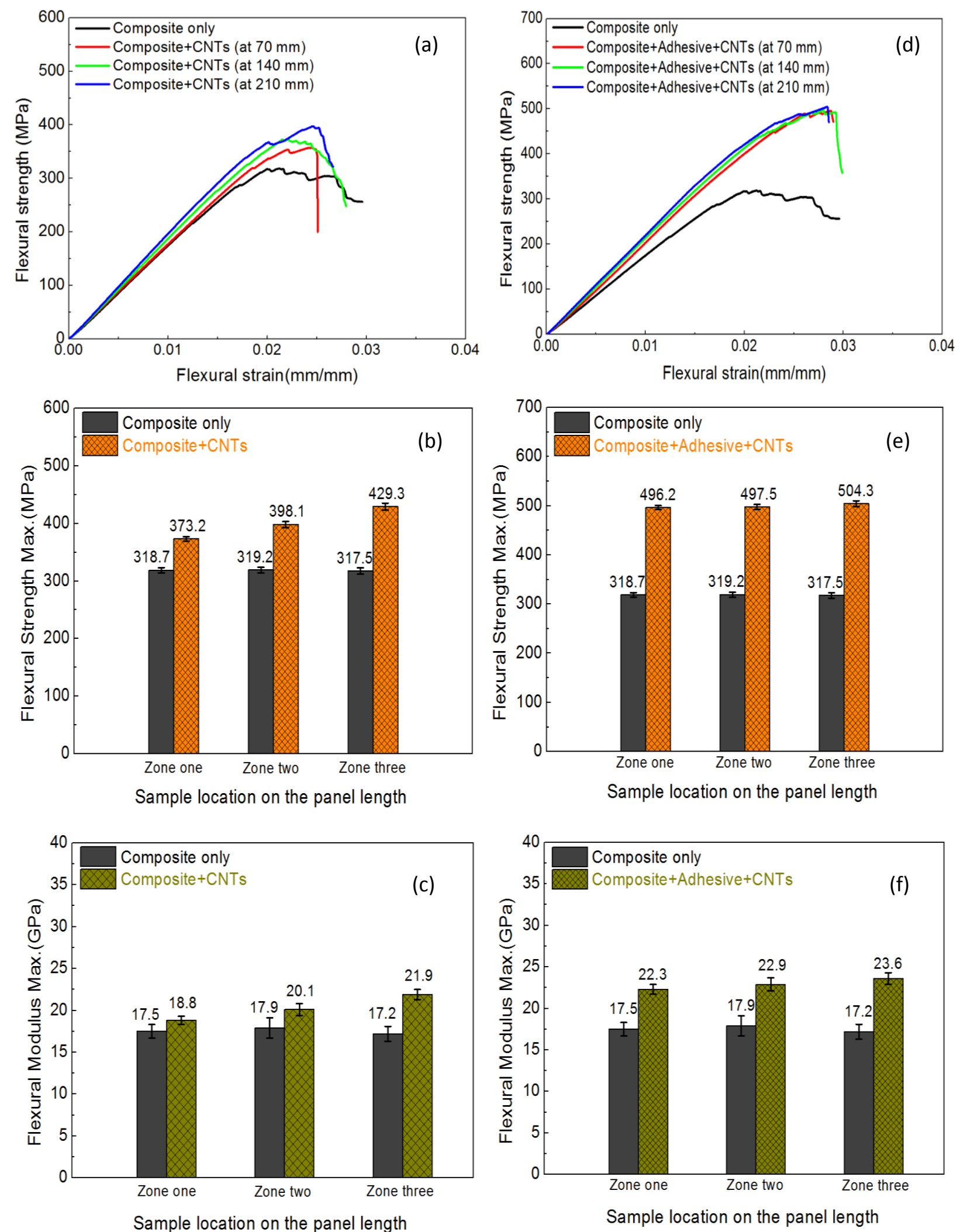

Figure 7. Representative individual flexural stress-strain curves measuring results, for maximum flexural strength and modulus properties of MWCNT-GE composites without adhesive (a, b, c) and with adhesive (d, e, f). 
Other studies have also investigated the improvement of composite properties through the addition of MWCNTs. Chang [18] studied the addition of MWCNTs on the mechanical properties of composite laminate/epoxy materials. Their results indicated an increase in the flexural strength properties of the resulting composite laminates. Their observed increase was $\approx$ $22.1 \%$ as compared to the unmodified condition which indicated a lower than in magnitude in compare with our study. In addition, Zhang et al [30] investigated the possible addition of different weight percentages of MWCNTs to the matrix material of Glass/fibre composites to improve the mechanical properties. They observed that after adding only $0.4 \mathrm{wt} . \%$ of MWCNTs to the matrix, an improved flexural strength resulted. Neither of these studies considered the use of bonding adhesive, as was used here. Therefore, the results of the present study indicated that greater improvements to the mechanical properties of the resultant composite are possible when a simple bonding adhesive is used to lock the MWCNTs into place. However, the results obtained in this study showed lower values compare with those obtained by other researchers. For instance, Rahmanian et al [31] used a CVD technique to deposit MWCNTs directly onto the fibre surfaces. Their results showed flexural strength and flexural modulus increases by $35 \%$ and $51 \%$ respectively. However, they did not study the variations in mechanical properties along the composite panels, they were taken results as an average through their study.
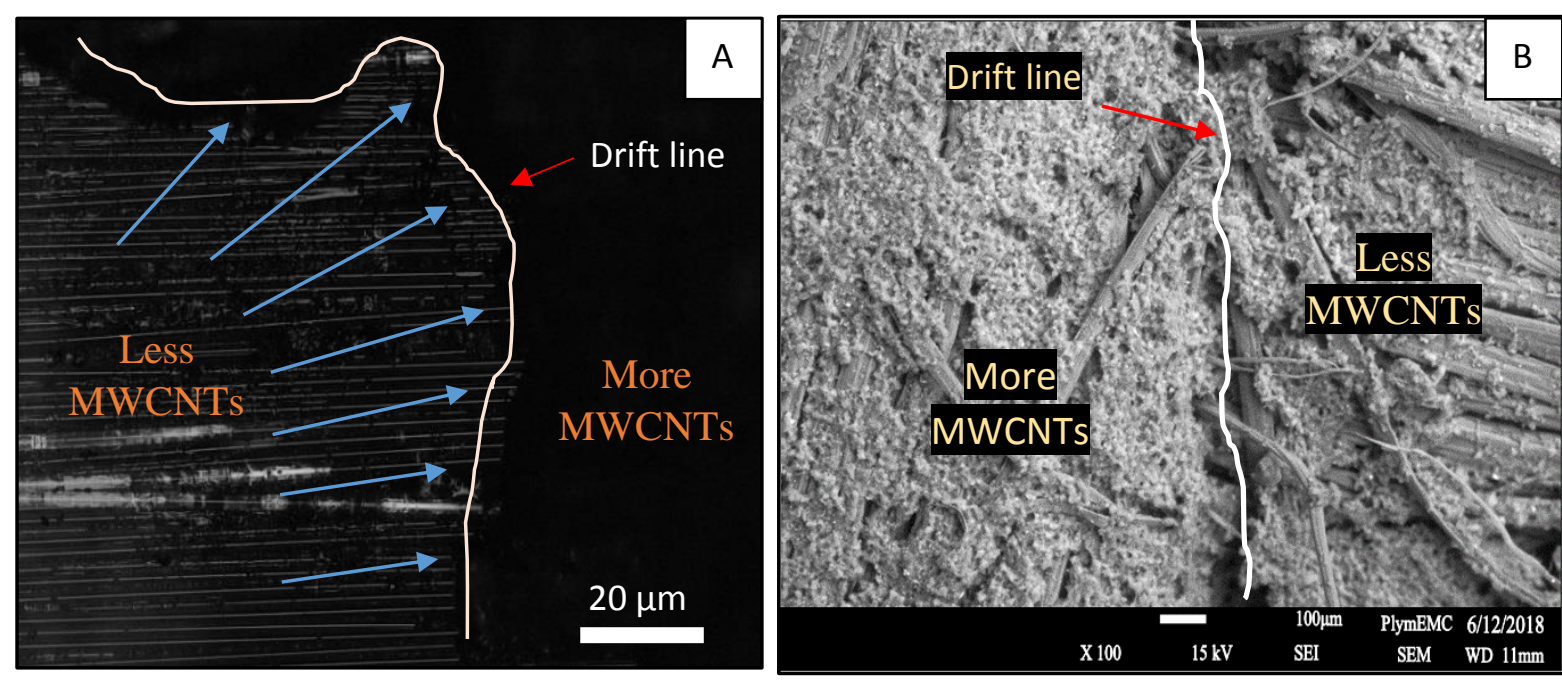

Figure 8. Illustration the mobilization of MWCNTs due to the epoxy flow rate (a) optical micrograph (b) SEM micrograph, both showing the drift line (white line), which separated the two phases. 


\subsection{In-situ Resistance Monitoring Test}

Incorporating MWCNTs into glass fibre reinforced composite material will make the surface of glass fibre electrically conductive [32]. This is due to the formation of continuous conductive pathways from MWCNTs on the surface of glass fibre. Consequently, the composite structure becomes very sensitive to external influences, particularly in terms of its internal electrical resistance. This provides the opportunity to create a sensor material, where changes in resistance can be monitored and related to any environmental or loading changes taking place. Here this change in the resistance behaviour also provides the opportunity to study, indirectly, the immovability of the MWCNTs in the interfacial region between matrix and reinforcement.

As described in section 2.2.2 the electrical tests were conducted on test panels to measure the changes in their resistance during the epoxy infusion process. Figure 9 shows the measured change in the electrical resistance with time for both types of treated (with and without bonding adhesive) MWCNTs-GE composites. Here it can be seen that a big difference of both types of composite test panels in term of changing in resistance was occurred during the resin infusion. Where no bonding adhesive was used to fix the MWCNTs in place, the resistance of the panel increased steadily in an almost linear manner from the start of the epoxy infusion process. The increase observed here is due to two possible phenomena; firstly the MWCNTs have been moved during the resin infusion so increasing the tunnelling distance between adjacent MWCNTs. This distance has a direct effect on the total composite resistance [33]. Secondly, the increase in temperature that occurs during the infusion process as the resin begins to chemically react with the coated composite layers $[34,35]$. In addition, where the bonding adhesive was used, a good stability and no obvious changes in resistance with time are observed up to 500 seconds. This stability is attributed to the adhesive material which plays an important role at this case, the viscosity of the adhesive seems preventing the MWCNTs to be drifted and leave their position during the resin infusion (see Figure $9 \mathrm{~b}$ insert). However, after which, a very low variation of electrical resistance was remarked when the time is exceed 500 seconds. This slight increment in resistance is probably not related to MWCNTs networks distortion, and more likely due to the temperature raise in the matrix, which dominates at this stage [36]. In summary, without using bonding adhesive to fix the MWCNTs to the fabric surfaces, the conducting MWCNT network structure can become distorted, so altering the 
conduction pathway between MWCNTs particles. In addition, the change in the MWCNTs areal density, brought about by the infusion process, may also have an influence on the electrical conductivity. Therefore, the influence of MWCNTs mobility and the potential sweep of the MWCNTs by the advancing infusion front must not be disregarded.

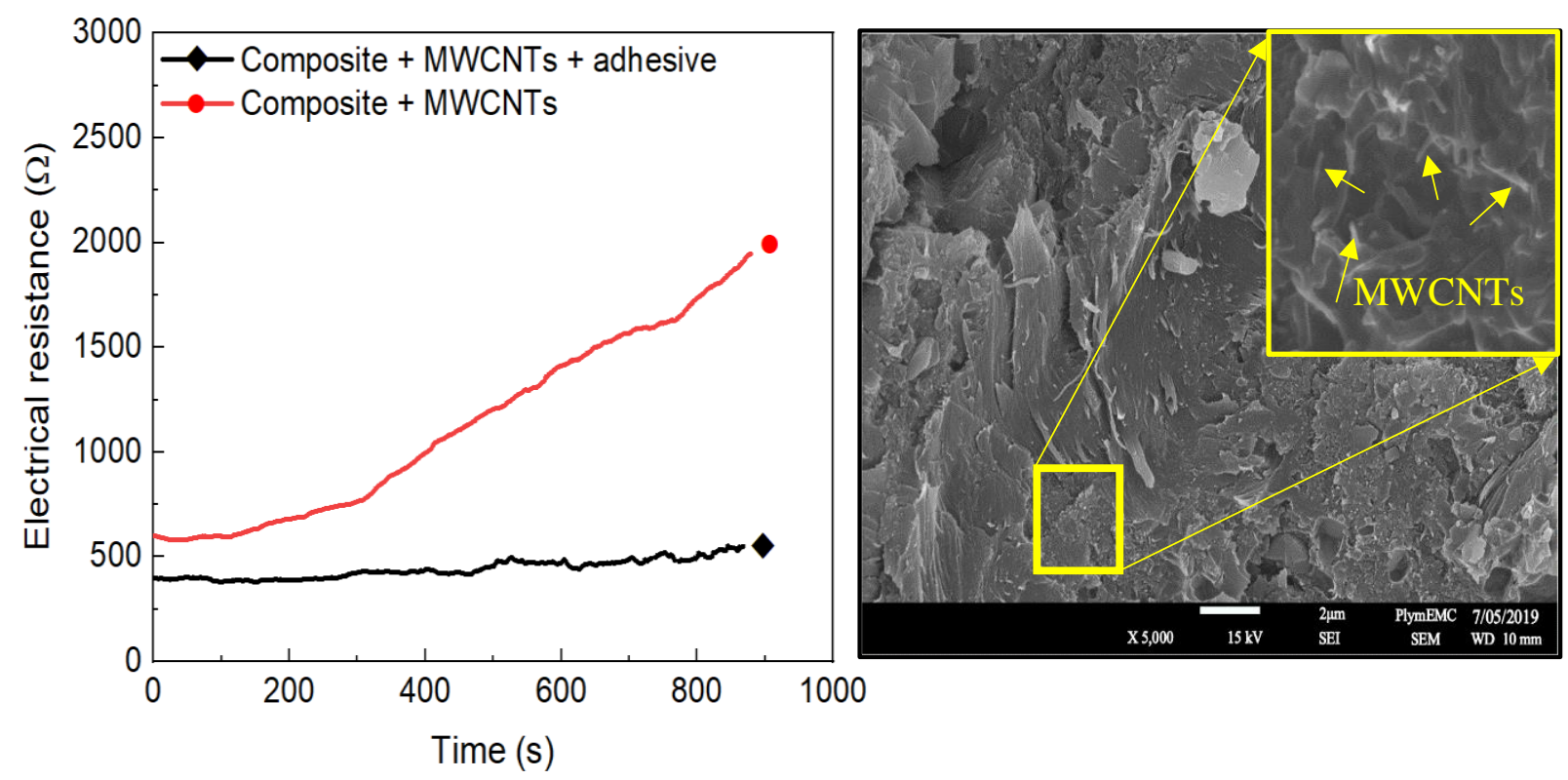

Figure 9. (a) Variation of electrical resistance with time during epoxy infusion for both type of fabricated self-sensing MWCNTs-GE nanocomposite composite and (b) SEM images for (adhesive) MWCNTs-GE composite.

\subsection{Electrical Conductivity Measurement}

The electrical conductivity of MWCNTs-GE composite is an important property. By monitoring the changing electrical conductivity, the fracture and strain can be predicted or sensed for structure health monitoring purposes. Figure 10 shows the variation in electrical conductivity for adhesive and non-adhesive composite at different zones locations. 


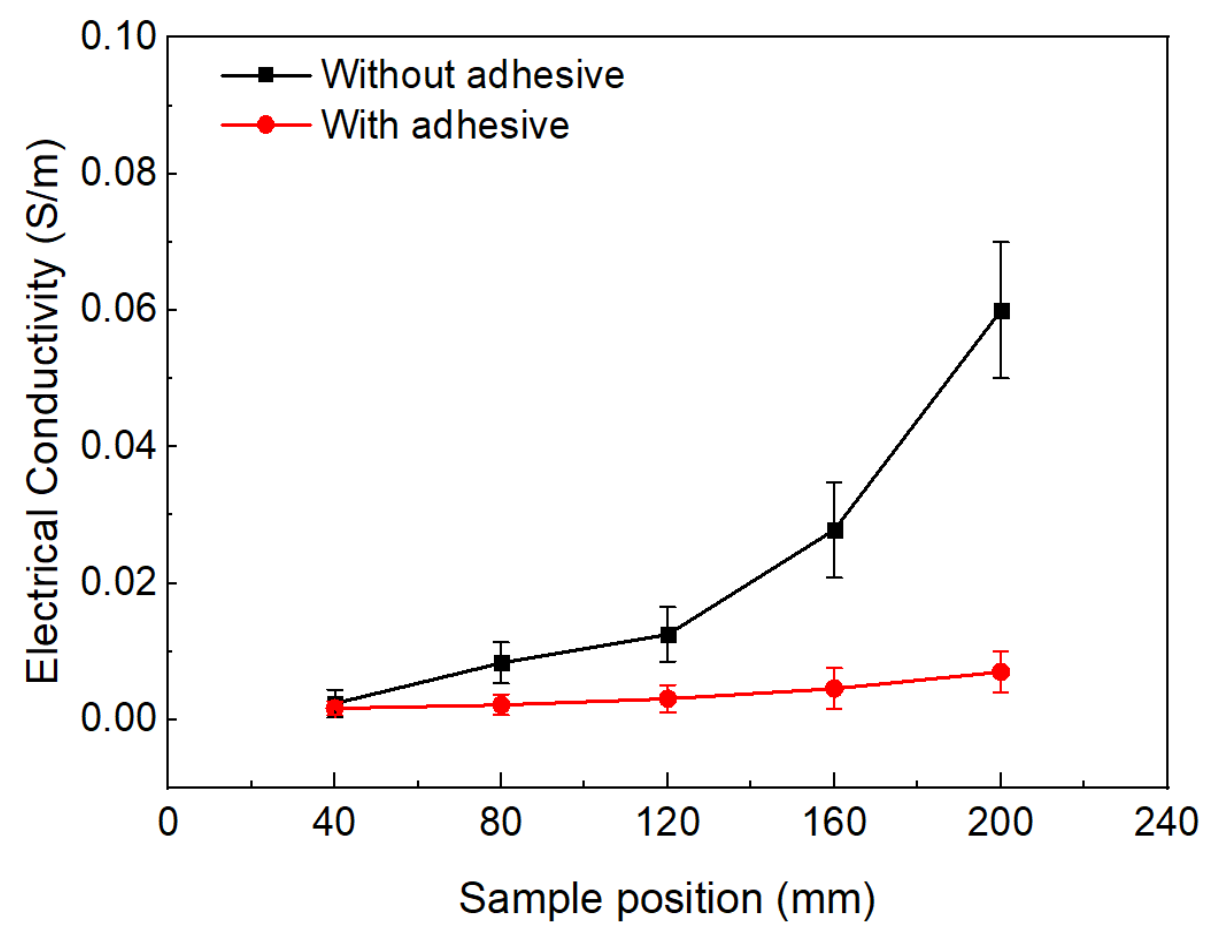

Figure 10. Variation in electrical conductivity against sample position.

It can be noted that the normalised conductivity of both types of specimens (with and without the use of bonding adhesive) increased in accordance with the sampling position i.e. the measured normalised conductivity values were highest at the end of the test panels and lowest at the beginning. This change was markedly higher where the bonding adhesive was not used due to the sweep of the MWCNTs, caused by the advancing epoxy infusion front, increasing the areal density of MWCNTs along the panel length. Thus, it is confirmed that any change in the MWCNT areal density, brought about by the infusion process, will affect the electrical conductivity of the composite. It should also be noted that a greater areal density of MWCNTs can also cause a reduction in the overall magnitude of the composite resistance $[33,37,38]$. This is considered [39-41] to be due to the reduced distance between MWCNTs improving the efficiency of the conduction pathway. Since MWCNTs are randomly distributed above the fabric laminate surface and then covered by the epoxy resin, it is not realistic to estimate the exact distance between every two adjacent MWCNTs. This distance along the panel's zones especially for (non-adhesive composite), can be calculated using Simon's theoretical model [42]. This is stated as; 


$$
\sigma_{m}=\left(\frac{e^{2} \sqrt{2 m \lambda}}{h^{2}}\right) \exp \left(\frac{4 \pi d \sqrt{2 m \lambda}}{h}\right)
$$

Where $\sigma_{\mathrm{m}}$ is the electrical conductivity polymer matrix, $e$ the electron electric charge density $\left(1.60217662 \times 10^{-19}\right.$ coulombs $), m$ the electron mass $\left(9.10938356 \times 10^{-31} \mathrm{~kg}\right), h$ indicated the Plank's constant $\left(6.62607004 \times 10^{-34} \mathrm{~m}^{2} \mathrm{~kg} / \mathrm{s}\right), \lambda$ is the energy barrier $(0.5 \mathrm{eV} \sim 5 \mathrm{eV})$ for most of the polymers (in this study, $\lambda$ was used $2.5 \mathrm{eV}$ [43]). It should be noted that the tunnelling distance $(d)$ is extremely dependent on both the matrix electrical conductivity and the energy barrier of the matrix (e). The electrical conductivity of most polymers is between $10^{-16}$ and $10^{-12}$ S.m ${ }^{-1}$. Therefore, polymers (e.g. epoxy) have usually been considered as insulating materials. Nevertheless, when the epoxy contains MWCNTs, the electrons can transfer between adjacent MWCNTs. This transfer could be defined, in a physical sense, as a quantum mechanical penetration of electrons through a potential barrier. By considering the MWCNTs conductivity as isotropic and randomly oriented, the electrical conductivity of MWCNTs-GE composite material can be given as follows [44];

$$
\sigma_{e}=\sigma_{m}+\frac{\beta f \sigma_{m} \sigma_{c}}{3+\left(\sigma_{m}+H(\beta \alpha)\right.}
$$

Where $\sigma_{\mathrm{e}}$ is the electrical conductivity of the CNTs composite (in this study experimentally calculated and represented in Figure 10, $\sigma_{\mathrm{c}}$ and $f$ indicate the electrical conductivity and the volume fraction of MWCNTs). It is well known that the electrical conductivity of MWCNTs is high and ranges from $10^{3} \mathrm{~S} . \mathrm{m}^{-1}$ to $10^{5} \mathrm{~S}^{-\mathrm{m}^{-1}}$ [45]. Therefore, in our simulations, we use $10^{4} \mathrm{~S} . \mathrm{m}^{-}$ 1 in accordance with published data. The parameter $\beta$ in equation (2) represents the nonstraightness of the CNTs, which can only apply here when the aspect ratio of the CNTs is high. According to the current properties of the MWCNTs in this study, the aspect ratio $(\alpha)$ is approximately 400 and this is considered low based on the recent studies [46], which have demonstrated that as the aspect ratio of CNTs increases, then the fibre rigidity will also increase. Therefore, the non-straightness is unity in this study. Moreover, $H$ is called the depolarisation factor and it reflects the influence of the CNTs aspect ratio $(\alpha)$ to conductivity and is expressed as [47]: 


$$
H(\alpha)=\left[\left(\alpha / \sqrt{\left(\alpha^{2}-1\right)}\right) \times \ln \left[\alpha+\sqrt{\left(\alpha^{2}-1\right)}\right]-1\right] /\left(\alpha^{2}-1\right)
$$

Since the volume fraction of the MWCNTs in this study is significantly altered due to their drift along the panel length then it can be considered as being high at the end of the panel (i.e. $0<f<$ 0.155), therefore, it was computed separately for each sample using Eq.(2). By substituting Eq. (2) and Eq. (3) in Eq.(1) by Maple software and after separating the variables , the relation between the tunnelling distance $(d)$ of CNT-CNT and their volume fraction is;

$$
d=\frac{\left(-2 \ln \left(-\sigma_{c} f-H+\sqrt{\sigma_{c}^{2} f^{2}+2 f\left(H+\sigma_{e}+3\right) \sigma_{c}+\left(H+\sigma_{e}+3\right)^{2}}+\sigma_{e}-3\right)-4(\ln e h)+\ln (8 \lambda m)\right) h \sqrt{2}}{16 \pi \sqrt{\lambda m}}
$$

The numerical results obtained using the above relationship, Eq. (4), are shown in Figure 11. It can be noted that the tunnelling distance significantly decreases as the volume fraction of MWCNTs of samples increases. This changing in volume fraction due to the drift of the MWCNTs effect and can be clearly seen in Figure 12. The SEM micrographs, Figure 12 shows the

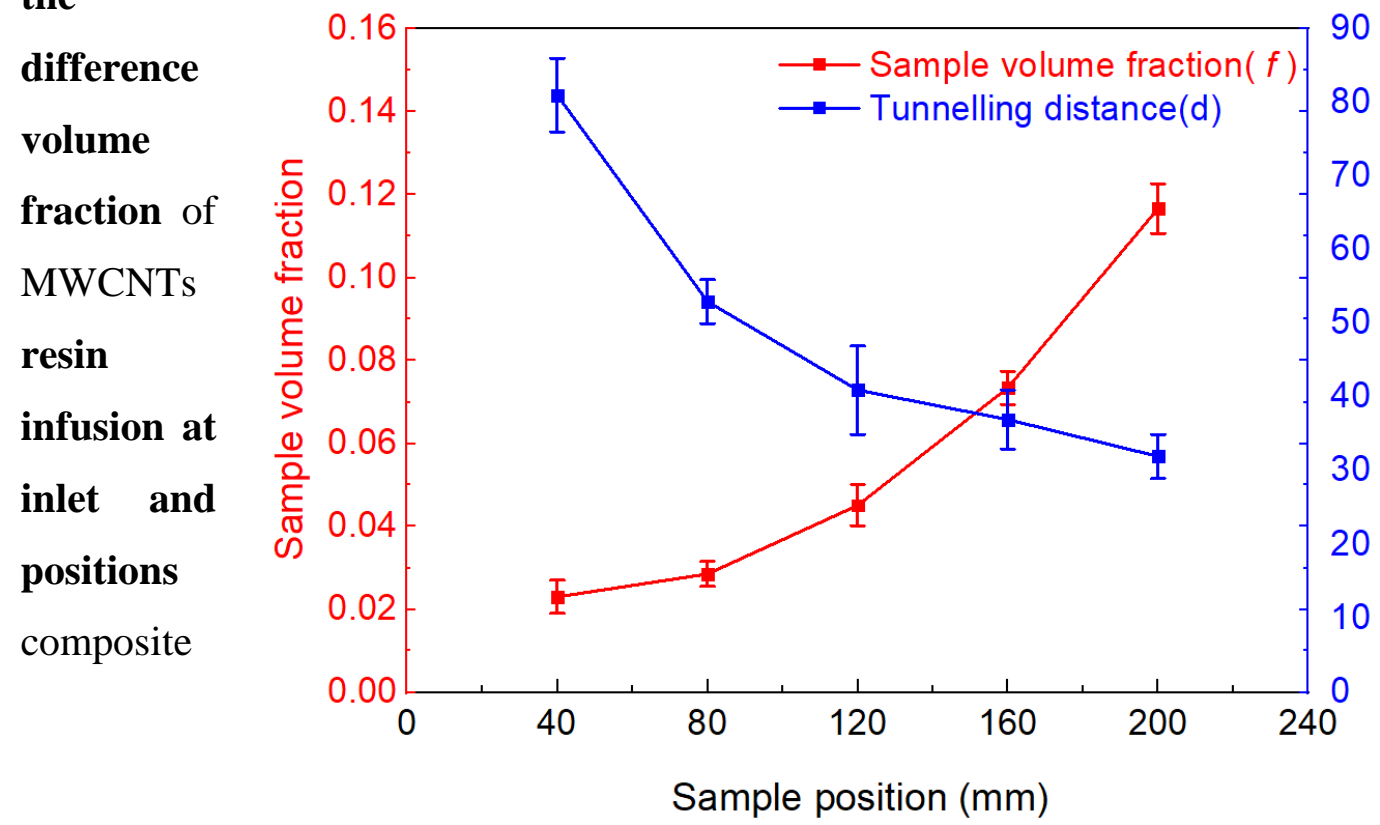

in the after the outlet of the panel.

Figure 11. Tunnelling distance of MWCNTs-GE composite samples as a function of the volume fraction for each sample. 


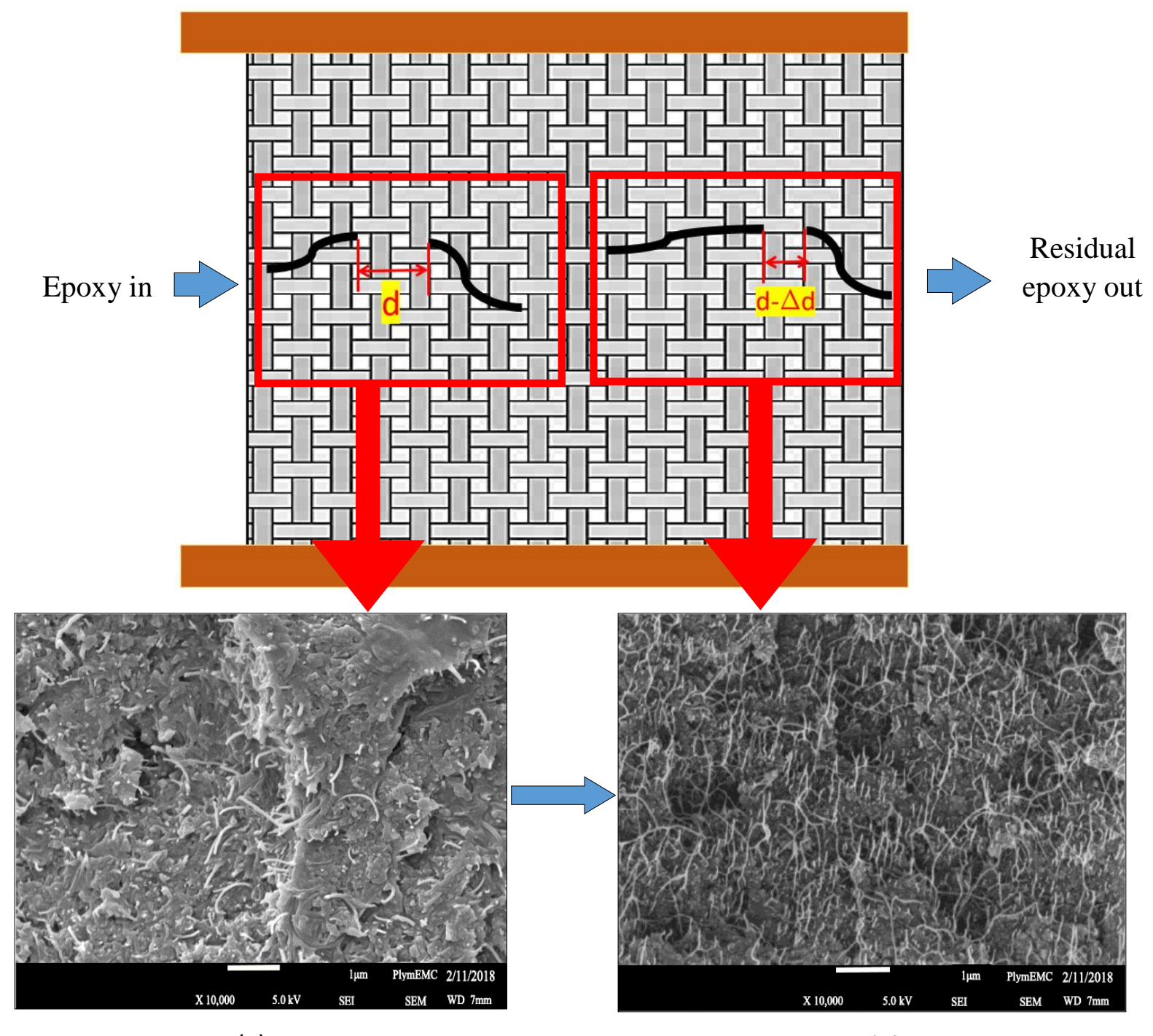

(a)

(b)

Figure 12. SEM micrographs of non-adhesive samples show MWCNTs volume fraction at (a) Panel inlet position, (b) End of panel (following infusion) 


\subsection{Piezoresistivity and Strain Sensitivity Properties}

The major purpose of this study was to investigate the stability of MWCNTs coated fabric during epoxy infusing processing. Figure 13 shows the normalised electric change $\left(\Delta R / R_{0}\right)$ - strain curves obtained from experimental results for both types of fabricated composites (with and without adhesive). Both types of fabricated composites show a strong piezoresistive response when subjected to flexural loading. Regardless of the MWCNTs (fixed with adhesive or not), the behaviour of the normalised electric resistance change linearly and in negative piezoresistive manner, i.e. the resistance change $\left(\Delta R / R_{0}\right)$ decreases linearly with the increase of applied strain for both types of fabricated composite as clearly shown in Figure $13 \mathrm{a}$, c. This change in $\left(\Delta \mathrm{R} / \mathrm{R}_{0}\right)$ with applied flexural strain can be interpreted as the breakdown of the conductive network paths between adjacent MWCNTs, which increases the inter-CNTs distance during applied strain. Moreover, the slope of the graphs shows the strain sensitivity i.e. gauge factor (GF) of the composite specimens at different zone locations along the composite panel length.

The gauge factor is significantly dependent on the volume fraction of the CNTs [48]. Therefore, the change in volume fraction of MWCNTs along the panel length, as expected and demonstrated in Figure 6, can be described as well as from the gauge factor calculations. Therefore, Figure 13b, d shows that the gauge factor for the samples in the zone one is higher than for samples located at the end of the composite panel i.e. (zone three) for both type of composites. For example, the gauge factor at zone one (for non-adhesive composite) is 3.67 which is higher by $31.6 \%$ and by $52.04 \%$ than zone two and zone three, respectively. This is due to the drift of MWCNTs causing the areal density to gradually increase along the composite panel, becoming highest in zone three. This is shown clearly in SEM images in Figure 12. It was proved that the samples with CNTs concentrations closer to the percolation threshold, are more sensitive and behave in a highly linear way $[49,50]$. This could be a reason for the higher gage factor values in zone one, which has a lower MWCNTs content after resin infusion and, therefore, closer to the percolation threshold.

Other studies [2, 33, 51-53] have also observed that when the volume fraction of MWCNTs increases, then the distance between neighbouring MWCNTs decreases and this finally leads to reducing the electrical resistance and strain sensitivity (GF) of the nanocomposite. However, for a composite coated with adhesively bonded MWCNTs, there is no big obvious change in zones 
gauge factors. This is due to the restricted movement of MWCNTs caused by the adhesive bonds between the MWCNTs and the fibres. This enables the MWCNTs to resist the pressure, which comes from the epoxy resin infusion.
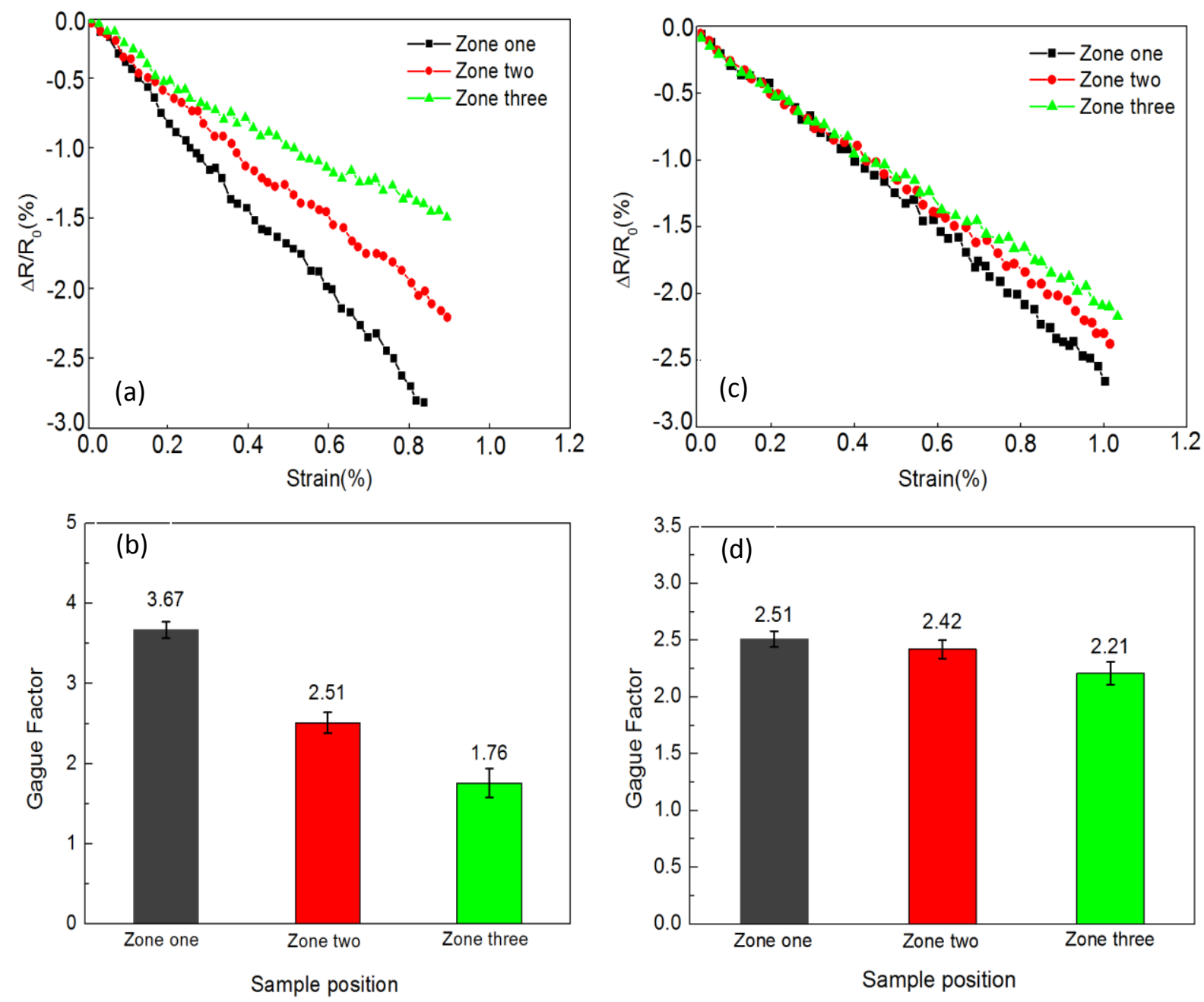

Figure 13. Normalised resistance change with strain and the gauge factors for different zones location. (a, b) without adhesive, (c, d) with adhesive. 


\section{Conclusions}

In summary, MWCNTs-GE composite panels were fabricated using vacuum infusion techniques. These panels were additional reinforced using MWCNTs, with these being incorporated into the composite structure with, and without, the use of a bonding adhesive. These panels were investigated, both experimentally and theoretically, and the following major conclusions can be drawn;

1. In general, both mechanical and electrical properties of the fabricated composites were greatly enhanced by the addition of MWCNTs to their structure, particularly where these were fixed in place using a simple bonding adhesive.

2. Flexural strength for the MWCNTs-GE composites, where the bonding adhesive was used, was improved compared to the reference by $\approx 37 \%$ for the samples located at the end of the panel, with changes less than $\approx 1.6 \%$ from this for the other zones. A $26 \%$ increase occurred for MWCNTs-GE composites, where no bonding adhesive was used, with large changes in values also being observed at first and second zones.

3. The flexural modulus increased by $\approx 27 \%$ and $\approx 21.4 \%$ for the composite with, and without, the use of bonding adhesive respectively.

4. The electrical conductivity measurements were also found to be high at the end of the MWCNTs-GE composites testes panels especially where no adhesive was used, with a maximum value of $\approx 0.06 \mathrm{~S} / \mathrm{m}$.

5. The epoxy infusion process also affected the electrical resistance and the gauge factors of the MWCNT-GE composites. This process brought about a change in the volume fraction of MWCNTs along the length of the composite. The electrical resistance was high and the gauge factor was low where no bonding adhesive was used at zone three.

6. Moreover, due to the drift of the MWCNTs to the end of the non-adhesive panel, the interparticle tunnelling distances between the MWCNTs have been determined by the theoretical analysis. The obtained results showed that there is an inverse relationship between the tunnelling distance and volume fraction of the MWCNTs. The samples have a high MWCNTs volume fraction at the end of panels and exhibited a massive reduction in the MWCNTs tunnelling distance.

7. From the results obtained, a variation in both (with and without adhesive) MWCNTs-GE composites properties of the test panels was observed to take place according to where 
the test specimens were taken from the fabricated panels. Test specimens taken from zone three positions obtained higher mechanical, electrical properties and lower strain sensitivity than those taken from zone one.

\section{Acknowledgement}

The authors would like to thank the Iraqi ministry of oil to funding this project under Grant No (SL-146-15). The authors appreciate the support of school of engineering staff and laboratories at the University of Plymouth to carry out all the required tests.

\section{References}

[1] Agarwal BD, Broutman LJ, Chandrashekhara K. Analysis and performance of fiber composites: John Wiley \& Sons; 2017.

[2] Al-Bahrani M, Aljuboury M, Cree A. Damage sensing and mechanical properties of laminate composite based MWCNTs under anticlastic test. Materials Research Express. 2018;6:035704.

[3] Kwon YJ, Kim Y, Jeon H, Cho S, Lee W, Lee JU. Graphene/carbon nanotube hybrid as a multi-functional interfacial reinforcement for carbon fiber-reinforced composites. Composites Part B: Engineering. 2017;122:23-30.

[4] Shindo Y, Kuronuma Y, Takeda T, Narita F, Fu S-Y. Electrical resistance change and crack behavior in carbon nanotube/polymer composites under tensile loading. Composites Part B: Engineering. 2012;43:39-43.

[5] Sharma S, Hussain S, Singh S, Islam S. MWCNT-conducting polymer composite based ammonia gas sensors: A new approach for complete recovery process. Sensors and Actuators B: Chemical. 2014;194:213-9.

[6] Zhang H, Bilotti E, Peijs T. The use of carbon nanotubes for damage sensing and structural health monitoring in laminated composites: a review. Nanocomposites. 2015;1:167-84. 
[7] Gallo GJ, Thostenson ET. Electrical characterization and modeling of carbon nanotube and carbon fiber self-sensing composites for enhanced sensing of microcracks. Materials today communications. 2015;3:17-26.

[8] Oh J, Yang JC, Kim J-O, Park H, Kwon SY, Lee S, et al. Pressure Insensitive Strain Sensor with Facile Solution-Based Process for Tactile Sensing Applications. ACS nano. 2018;12:7546-53.

[9] Hu C, Li Z, Wang Y, Gao J, Dai K, Zheng G, et al. Comparative assessment of the strainsensing behaviors of polylactic acid nanocomposites: reduced graphene oxide or carbon nanotubes. Journal of Materials Chemistry C. 2017;5:2318-28.

[10] Gaztelumendi I, Chapartegui M, Seddon R, Flórez S, Pons F, Cinquin J. Enhancement of electrical conductivity of composite structures by integration of carbon nanotubes via bulk resin and/or buckypaper films. Composites Part B: Engineering. 2017;122:31-40.

[11] Iijima S. Helical microtubules of graphitic carbon. nature. 1991;354:56-8.

[12] Cao X, Wei X, Li G, Hu C, Dai K, Guo J, et al. Strain sensing behaviors of epoxy nanocomposites with carbon nanotubes under cyclic deformation. Polymer. 2017;112:1-9.

[13] Shi S, Wang L, Pan Y, Liu C, Liu X, Li Y, et al. Remarkably Strengthened microinjection molded linear low-density polyethylene (LLDPE) via multi-walled carbon nanotubes derived nanohybrid shish-kebab structure. Composites Part B: Engineering. 2019.

[14] Li Z, Wang B, Qin X, Wang Y, Liu C, Shao Q, et al. Superhydrophobic/superoleophilic polycarbonate/carbon nanotubes porous monolith for selective oil adsorption from water. ACS Sustainable Chemistry \& Engineering. 2018;6:13747-55.

[15] Lin C, Hu L, Cheng C, Sun K, Guo X, Shao Q, et al. Nano-TiNb2O7/carbon nanotubes composite anode for enhanced lithium-ion storage. Electrochimica Acta. 2018;260:65-72.

[16] Zhou B, Li Y, Zheng G, Dai K, Liu C, Ma Y, et al. Continuously fabricated transparent conductive polycarbonate/carbon nanotube nanocomposite films for switchable thermochromic applications. Journal of Materials Chemistry C. 2018;6:8360-71.

[17] Cheng C, Fan R, Ren Y, Ding T, Qian L, Guo J, et al. Radio frequency negative permittivity in random carbon nanotubes/alumina nanocomposites. Nanoscale. 2017;9:5779-87.

[18] Chang MS. An investigation on the dynamic behavior and thermal properties of MWCNTs/FRP laminate composites. Journal of Reinforced Plastics and Composites. 2010;29:3593-9. 
[19] Liu W, Wei B, Xu F. Investigation on the mechanical and electrical properties of carbon nanotube/epoxy composites produced by resin transfer molding. Journal of Composite Materials. 2017;51:2035-43.

[20] Frømyr TR, Hansen FK, Olsen T. The optimum dispersion of carbon nanotubes for epoxy nanocomposites: evolution of the particle size distribution by ultrasonic treatment. Journal of Nanotechnology. 2012;2012.

[21] De Greef N, Zhang L, Magrez A, Forró L, Locquet J-P, Verpoest I, et al. Direct growth of carbon nanotubes on carbon fibers: Effect of the CVD parameters on the degradation of mechanical properties of carbon fibers. Diamond and Related Materials. 2015;51:39-48.

[22] Deng C, Jiang J, Liu F, Fang L, Wang J, Li D, et al. Influence of carbon nanotubes coatings onto carbon fiber by oxidative treatments combined with electrophoretic deposition on interfacial properties of carbon fiber composite. Applied Surface Science. 2015;357:127480 .

[23] Jamnani BD, Hosseini S, Rahmanian S, Rashid SA, Balavandy SK. Grafting carbon nanotubes on glass fiber by dip coating technique to enhance tensile and interfacial shear strength. Journal of Nanomaterials. 2015;16:306.

[24] Davis DC, Wilkerson JW, Zhu J, Ayewah DO. Improvements in mechanical properties of a carbon fiber epoxy composite using nanotube science and technology. Composite Structures. 2010;92:2653-62.

[25] Xu Z, Huang Y, Zhang C, Liu L, Zhang Y, Wang L. Effect of $\gamma$-ray irradiation grafting on the carbon fibers and interfacial adhesion of epoxy composites. Composites Science and Technology. 2007;67:3261-70.

[26] Liu H, Li Q, Zhang S, Yin R, Liu X, He Y, et al. Electrically conductive polymer composites for smart flexible strain sensors: a critical review. Journal of Materials Chemistry C. 2018;6:12121-41.

[27] Wu Z, Cui H, Chen L, Jiang D, Weng L, Ma Y, et al. Interfacially reinforced unsaturated polyester carbon fiber composites with a vinyl ester-carbon nanotubes sizing agent. Composites Science and Technology. 2018;164:195-203.

[28] Gu H, Zhang H, Ma C, Xu X, Wang Y, Wang Z, et al. Trace electrosprayed nanopolystyrene facilitated dispersion of multiwalled carbon nanotubes: simultaneously strengthening and toughening epoxy. Carbon. 2019;142:131-40. 
[29] He Y, Yang S, Liu H, Shao Q, Chen Q, Lu C, et al. Reinforced carbon fiber laminates with oriented carbon nanotube epoxy nanocomposites: magnetic field assisted alignment and cryogenic temperature mechanical properties. Journal of colloid and interface science. 2018;517:40-51.

[30] Zhang X, Wang P, Neo H, Lim G, Malcolm AA, Yang E-H, et al. Design of glass fiber reinforced plastics modified with CNT and pre-stretching fabric for potential sports instruments. Materials \& Design. 2016;92:621-31.

[31] Rahmanian S, Thean K, Suraya A, Shazed M, Salleh MM, Yusoff H. Carbon and glass hierarchical fibers: influence of carbon nanotubes on tensile, flexural and impact properties of short fiber reinforced composites. Materials \& Design. 2013;43:10-6.

[32] Mittal G, Dhand V, Rhee KY, Park S-J, Lee WR. A review on carbon nanotubes and graphene as fillers in reinforced polymer nanocomposites. Journal of Industrial and Engineering Chemistry. 2015;21:11-25.

[33] Hu N, Fukunaga H, Atobe S, Liu Y, Li J. Piezoresistive strain sensors made from carbon nanotubes based polymer nanocomposites. Sensors. 2011;11:10691-723.

[34] Danisman M, Tuncol G, Kaynar A, Sozer EM. Monitoring of resin flow in the resin transfer molding (RTM) process using point-voltage sensors. Composites Science and Technology. 2007;67:367-79.

[35] Njuguna MK, Galpaya D, Yan C, Colwell JM, Will G, Hu N, et al. Investigation on Temperature-Dependent Electrical Conductivity of Carbon Nanotube/Epoxy Composites for Sustainable Energy Applications. Journal of nanoscience and nanotechnology. 2015;15:6957-64.

[36] Sorrentino L, Esposito L, Bellini C. A new methodology to evaluate the influence of curing overheating on the mechanical properties of thick FRP laminates. Composites Part B: Engineering. 2017; 109:187-96.

[37] Shen J, Buschhorn S, De Hosson JTM, Schulte K, Fiedler B. Pressure and temperature induced electrical resistance change in nano-carbon/epoxy composites. Composites Science and Technology. 2015;115:1-8.

[38] Bouhamed A, Al-Hamry A, Müller C, Choura S, Kanoun O. Assessing the electrical behaviour of MWCNTs/epoxy nanocomposite for strain sensing. Composites Part B: Engineering. 2017;128:91-9. 
[39] Liu H, Gao J, Huang W, Dai K, Zheng G, Liu C, et al. Electrically conductive strain sensing polyurethane nanocomposites with synergistic carbon nanotubes and graphene bifillers. Nanoscale. 2016;8:12977-89.

[40] Sun K, Xie P, Wang Z, Su T, Shao Q, Ryu J, et al. Flexible polydimethylsiloxane/multiwalled carbon nanotubes membranous metacomposites with negative permittivity. Polymer. 2017;125:50-7.

[41] Zhang S, Liu H, Yang S, Shi X, Zhang D, Shan C, et al. Ultrasensitive and Highly Compressible Piezoresistive Sensor Based on Polyurethane Sponge Coated with Cracked Cellulose Nanofibril/Silver Nanowire Layer. ACS applied materials \& interfaces. 2019.

[42] Perets Y, Aleksandrovych L, Melnychenko M, Lazarenko O, Vovchenko L, Matzui L. The Electrical Properties of Hybrid Composites Based on Multiwall Carbon Nanotubes with Graphite Nanoplatelets. Nanoscale research letters. 2017;12:406.

[43] Hu N, Karube Y, Arai M, Watanabe T, Yan C, Li Y, et al. Investigation on sensitivity of a polymer/carbon nanotube composite strain sensor. Carbon. 2010;48:680-7.

[44] Deng F, Zheng Q. Interaction models for effective thermal and electric conductivities of carbon nanotube composites. Acta Mechanica Solida Sinica. 2009;22:1-17.

[45] Lekawa- Raus A, Patmore J, Kurzepa L, Bulmer J, Koziol K. Electrical properties of carbon nanotube based fibers and their future use in electrical wiring. Advanced Functional Materials. 2014;24:3661-82.

[46] Kumar RM, Sharma SK, Kumar BM, Lahiri D. Effects of carbon nanotube aspect ratio on strengthening and tribological behavior of ultra high molecular weight polyethylene composite. Composites Part A: Applied Science and Manufacturing. 2015;76:62-72.

[47] Deng F, Zheng Q-S, Wang L-F, Nan C-W. Effects of anisotropy, aspect ratio, and nonstraightness of carbon nanotubes on thermal conductivity of carbon nanotube composites. Applied Physics Letters. 2007;90:021914.

[48] Rahman R, Servati P. Effects of inter-tube distance and alignment on tunnelling resistance and strain sensitivity of nanotube/polymer composite films. Nanotechnology. 2012;23:055703.

[49] García-Macías E, D'Alessandro A, Castro-Triguero R, Pérez-Mira D, Ubertini F. Micromechanics modeling of the uniaxial strain-sensing property of carbon nanotube cement-matrix composites for SHM applications. Composite Structures. 2017;163:195-215. 
[50] D'Alessandro A, Rallini M, Ubertini F, Materazzi AL, Kenny JM. Investigations on scalable fabrication procedures for self-sensing carbon nanotube cement-matrix composites for SHM applications. Cement and Concrete Composites. 2016;65:200-13.

[51] Yin G, Hu N, Karube Y, Liu Y, Li Y, Fukunaga H. A carbon nanotube/polymer strain sensor with linear and anti-symmetric piezoresistivity. Journal of composite materials. 2011;45:1315-23.

[52] Ferreira A, Martínez M, Ansón-Casaos A, Gómez-Pineda L, Vaz F, Lanceros-Mendez S. Relationship between electromechanical response and percolation threshold in carbon nanotube/poly (vinylidene fluoride) composites. Carbon. 2013;61:568-76.

[53] Li Y, Zhou B, Zheng G, Liu X, Li T, Yan C, et al. Continuously prepared highly conductive and stretchable SWNT/MWNT synergistically composited electrospun thermoplastic polyurethane yarns for wearable sensing. Journal of Materials Chemistry C. 2018;6:225869.

[54] British Standards Institute (BSI).1998. BS EN ISO 14125:1998+A1:2011. Fibre reinforced plastic composites-Determination of flexural properties. London: British Standards Institute. 